\title{
An Evaluation of the Impact of Media Campaign Against Female Genital Mutilation (FGM) in the Rural Communities of Enugu State, Nigeria
}

\author{
Joseph Oluchukwu Wogu ${ }^{1}$, Chinenye Amonyeze ${ }^{2}$, Raphael Oluwasina Babatola Folorunsho ${ }^{3} \&$ Henry E. Aloh ${ }^{4}$ \\ ${ }^{1}$ Department of Mass Communication, University of Nigeria, Nsukka, Enugu State, Nigeria \\ ${ }^{2}$ Department of Theatre and Film Studies, University of Nigeria, Nsukka, Enugu State, Nigeria \\ ${ }^{3}$ Family Medicine Department, Tawam Hospital, United Arab Emirates (UAE) \\ ${ }^{4}$ Health Economics and Research Unit, Department of Health Services, Alex Ekwueme Federal University \\ Ndufu-Alike Ikwo, Ebonyi State, Nigeria \\ Correspondence: Chinenye Amonyeze, Department of Theatre and Film Studies, University of Nigeria, Nsukka, \\ Enugu State, Nigeria. E-mail: chinenye.amonyeze@unn.edu.ng
}

\author{
Received: August 18, 2019 Accepted: October 31, 2019 Online Published: November 10, 2019 \\ doi:10.5539/gjhs.v11n14p37 URL: https://doi.org/10.5539/gjhs.v11n14p37
}

\begin{abstract}
This paper investigates the impact of media campaign against Female Genital Mutilation (FGM) in the rural areas of Enugu State. One hundred and sixty three women attending the antenatal clinics in six rural communities and twenty-four heads of Women groups were selected as sample for this cross-sectional survey. Structured questionnaire and interview were used to collect data while analysis of the data was done with SPSS version 20.0. The results reveal among others that the media campaign against FGM in Enugu state is ineffective. It further reveals that cultural values (51\%), poor network reception (23\%), epileptic power supply (18\%), inaccessible media, and the nature of the content of the campaign are responsible for the ineffectiveness. Given the findings, the researchers recommends the modernization of the media and the contents of its FGM campaign for rural reach/accessibility, the development of pro-Igbo cultural programmes against FGM practice, and the use of visual methods to establish/prove the relationship between FGM, infections/diseases and maternal deaths. Further empirical research on FGM - maternal health care in Enugu State is recommended.
\end{abstract}

Keywords: Female Genital Mutilation, media programmes, culture, tradition, rural community, rural accessibility

\section{Introduction}

Nigeria has more than two hundred and fifty ethnic nationalities with diverse cultures that dictate people's patterns of behaviours (Uturu, 2009). The dynamic nature of the society demands that these patterns of behaviour should be modified or eradicated for the sake of modernization and development. The traditional practice of Female Genital Mutilation (FGM) is one of these behaviours, but unlike other distinctive behaviours, it is a prevalent practice in all the Nigerian ethnic nationalities (Kolawole \& Anke, 2012; Okpanchi, 2005). Ibekweet al. (2012), Mandara (2005), the US Department of State (2001), and Shah, Susan, and Furcroy (2009) observed that the practices of female genital mutilation (FGM) as well as the campaign to eradicate the practice are universal phenomena. Female genital mutilation, which is also known as female circumcision, is a set of procedures used to remove part or all of the external female genitals.

The beginning of this cultural practice is conceivably unknown, but generations have continued this exercise with the notion that it regulates woman's libido, promiscuity and ability to enjoy sex, while also enhancing fertility and childbirth. People that do not believe in these perceived benefits of cutting this most essential part of women organ, still subject their children to female genital mutilation because of cultural orientation, to ensure their acceptability in the society and improve their chances of marriage (La-Barbera, 2009; Ahmadi, 2013). Thirdly, the practice of FGM has been a source of personal income for the elderly female members of the community, barbers, traditional healers and birth attendants who carry out the procedure (BAOBAB for Women's Human Rights (BAOBAB), 2002).

Insight (2010), and Mackie and Le Jeune (2009) observed that family honour and social expectations, social norms, 
the fear of moral judgements and social sanctions, the desire to protect girls and to give them the best possible chance to have a future are the factors that perpetuate the practice of FGM in Egypt, Ethiopia, Kenya, Senegal and the Sudan. Therefore, in communities where it is practised, FGM is not viewed as a dangerous act and a violation of rights, but as a necessary step to raise a girl 'properly', to protect her and, in many instances, to make her eligible for marriage. Parents get their daughter's genital mutilated so as to secure the best possible future for them (Insight, 2010). However, Alo and Adetula (2015), Ogionwo (2003) among many other scholars contend that the practice is highly inimical to health because it causes the growth of cyst, the development of bladder fistulae, which can lead to infertility, illness, bleeding and even death, pain during sexual intercourse, shock, urine retention, damage to the urethra, and ulceration of the genital region. Further, Nabudere (2005) and Okeke et al. (2012) argue that the practice is a serious human rights violation.

The antagonists of FGM argue that it is detrimental to health and against human rights, and that the universality of human rights must apply in FGM. On the other hand, the exponents of the practice like Cassman (2008) argued that human rights and rules are subject to cultural provisions, that is, cultural relativism. Therefore, universalizing FGM eradication is tantamount to destroying cultural diversity and enthroning western culture, which the campaign seems to be propagating. Apenda and Terna (2009) observed that people may consider it as appropriate within a particular culture, and may not in another culture. This creates a conflict of cultural values and norms in the campaign against FGM that tends to affect the result of the campaign negatively.

McGuire (2002), Scott (2005) and Okpando (2004) contend that it is pertinent to sensitize people on the harmful effects of female genital mutilation. Beatrice Eluaka of the Federal Ministry of Health announced, on 16 May 2003, a National policy and plan of action on the elimination of FGM that was approved by the Federal Executive Council on 30 April (2003). In line with this policy, Nwokolo (2009) and Sharon (2006) advocate for the establishment of guidance and counselling offices in various communities to assist in the sensitization process. In addition to this, many International and National Non-Governmental Organizations (NGOs) embarked on educational and mobilization campaigns to eradicate the practice of FGM in Nigeria, albeit using the mass media as their channel of communication (Efua, 1994).

Many states in Nigeria, particularly Enugu State adopted different strategies to sensitize and mobilize the rural people against FGM practice. In Enugu State, enabling laws that criminalize the practice of FGM were enacted, while relevant agencies embarked on organizing workshops and seminars, introduced mass media advocacy and activities, and sponsorship of civil society activities on the eradication of FGM in the state (Babalola et al, 2006). For example, The National Association of Women Journalists (NAWOJ) launched a media programme known as Ndukaku (an Igbo expression, meaning, health is better than wealth), while Women Action Research Organization (WARO) engaged in awareness campaign, community dialogue about the practice, cultural and socio-economic issues that reinforced the practice, and community advocacy for people to abandon the practice. The electronic media, which comprise television, radio, and film, were extensively used in sensitising and mobilising the rural populace against the practice of FGM. Media stations such as Nigerian Television Authority (NTA), Enugu State Television (ETV), Enugu State Broadcasting Service (ESBS), and Coal City FM, are the major stations involved in the campaign to eradicate FGM.

In spite of these efforts and approaches, Anyamene, Nwokolo, and Anyachebelu (2006), Abubakar et al (2004), and the Women's Rights to Education Programme (WREP) (2006) note that the practice of FGM remains widespread throughout Nigerian rural and urban communities. Scholars blame government and external bodies' collaboration and the imposition of the anti-FGM programmes as the reason for rural people's intransigence. Others blame government's use of the media as a tool for propaganda and the associated lack of press freedom for the ineffectiveness of media campaign against FGM. Ofor and Ofole (2010) observe that people mock such programmes and even dare any law enforcement agent to arrest them, owing to these factors. Consequently, the primary objectives of this paper are to investigate the extent of media - rural people's interaction, and the impact of the interaction on the practice of FGM with a view to identify the major problems of mass media communication in Enugu State. Thematically, this study is concerned with media activities against the practice of FGM, while it is geographically restricted to the rural areas of Enugu State.

\subsection{Significance of the Study}

This study has both theoretical and empirical significance. Empirically, it exposes the major pitfalls and limitations in the media campaign against FGM in Enugu State. This exposition enables key stakeholders in the media industry to re-assess the programme and embark on innovative policies that will enhance media - rural effects. In addition, the data provided by the study shall enable the government to evaluate the impact of culture on the FGM laws and integrate cultural institutions in the amendment of the laws for purposes of effectiveness. Theoretically, 
this study provides the data on FGM in the rural areas of Enugu State, thereby enhancing comparative study of the phenomena with other areas in the South-East, and the other geo-political zones in Nigeria. In addition to this, the work shall provide data, which complements available literature, and also serve as a reference material to assist other researchers in related inquiries.

\section{Literature Review}

The media have been generally used in Nigeria to effect behavioural changes, promote particular attitudes, behaviours and social norms since the 1970s (Tufte \& Mefalopulos, 2009). It is a veritable instrument used to pursue attitudinal behaviours and societal changes through diffusion approach. The approach includes information dissemination, large-scale media campaigns, and other one-way communications. These are structured by entertainment education known as 'Edutainment'. This is a communication process that aims to entertain and educate for purposes of increasing audience knowledge, change attitudes, social norms, and behaviour (UNICEF, 2005). Edutainment allows the audiences to experience excitement, and also provides for role modelling of positive norms, attitudes and behaviours (Barker, Ricardo, \& Nascimento, 2007). Radio and television programmes are the most useful channel for actualizing this project.

The mass media through their programmes or activities have widened the potentials for the interconnectedness of citizens to one another and to their government, thereby making government processes more transparent to the citizenry. They provide the avenues for greater public awareness and public participation in government policies (Pool, 1990). Mortensen and Serritzlew (2004, p. 17) demonstrate that "the media are important for understanding the political agenda and the framing of decisions about special [or sensational] issues, but 'normal' politics and the broader policy priorities [or governmental issues] are largely unaffected". Although Barber (1996) on the other hand, observes that the media could be used as instruments of propaganda to manipulate the public and foist preferred political values, which enhance regime support and political legitimacy on the people. This observation buttresses the point that the media is an effective and a veritable tool for propagating government policies.

The above collaboration between the media and the public has a significant effect on the outcome of government policies. It also helps policy makers to manage media activities towards the maximization of positive publicity for their policies (Protess et al., 1991). Consequently, the media are tools for decentralizing information and actualising individual's empowerment. They also help to expand the number of channels through which individuals obtain news and views, as well as change who owns, produces and controls the content of news. The media strengthen civil society and social movements at the expense of the state by increasing their ability to distribute message, mobilize support, and influence public discourse. The literature as reviewed portends that the media are effective instruments for propagating government's anti-FGM policy in Enugu State.

\section{Theoretical Framework}

This paper adopts a combination of two theories, namely, the agenda setting theory and the framing theory of media role as its framework of analysis. The main proposition of the agenda setting theory is salience transfer. Salience transfer refers to the ability of the news media to transfer issues of importance from their news agenda to public agenda. Through this, they influence people's perceptions on what the most important issues of the day should be (Ogbuoshi, 2011). This ability to influence the salience of topics on the public agenda is known as the agenda-setting role of the news media. Thus, since the media can set agenda for the public to follow, it becomes imperative to use the media to set the agenda of eradicating FGM in Enugu State. The theory helps in the understanding of the effects of new media content on individuals, particularly target audience (Kalu, 2010). The media can and do stimulate interest by providing the context that influence how people will talk about issues of public concern. This relates to the second theory adopted by this paper, the framing theory. The principle of framing theory is that the media focuses attention on certain events and then places them within a field of meaning. In this case, how an issue is presented (the frame) influences the choices people make (Asemah, 2011). This affects people's beliefs, attitudes and behaviours, by connecting them to a particular meaning or interpretation of an issue. These two theories enable this paper to assess the impact of the mass media on FGM practice in Enugu State.

\section{Method}

\subsection{Research Design/Study Area}

This paper employs cross-sectional survey wherein a sample population from the rural communities in Enugu State were asked questions through interviews and questionnaires concerning media access/programmes and the practice of FGM and their participation in the two. Enugu State comprises over two hundred and thirty five communities, which are delineated into three Senatorial Districts of Enugu East, Enugu West, and Enugu North. Over ninety percent $(90 \%)$ of these communities are rural communities with government health centres as the 
highest medical facilities available to the people. From these communities and their government health centres, a cross-sectional survey was conducted in six of them, which were randomly selected from the three Senatorial Districts. The research was carried out in accordance the tenets of the Helsinki Declaration, and approved by the Departmental Research Ethics Committee at the University of Nigeria, Nsukka. Verbal informed consent was obtained from all individuals included in this study.

\subsection{Population and Sample of the Study}

From each of the six communities and their government health centres randomly selected, the traditional heads of Women groups and all the women attending antenatal clinics were chosen as population, as well as the sample for the study. This is because the total is a manageable size for the study. The total number of the traditional heads of Women groups is twenty four, with the age of the women ranging from sixty eight years to eighty years. They were selected for interview because of their decades of motherhood and mentorship in the society.

On the other hand, all the women attending antenatal clinics in the six government health centres numbering one hundred and sixty three (163) served as respondents of the research questionnaires. The towns and the number of women attending antenatal clinics are Adani (20 women) and Obollo-Eke (32 women) in Enugu North senatorial district, Agbogo-Nike (27 women) and Akegbe-Ugwu (24 women) in Enugu East senatorial district, and Iwollo (26) and Inyi (33) in Enugu West senatorial district. Field survey was conducted between February 4, 2016 and July 27, 2016 to generate data.

\subsection{Instruments and Means of Data Generation}

During the inquiry, primary data was generated with the aid of structured questionnaire with five-point Likert scale format and interviews. The structured questionnaire was divided into two sections, namely: the section that seeks information concerning the basic socio-demographic indices of the respondents, while the second section seeks answers to questions relating to the respondents' awareness of media programmes against the practice of FGM, respondents' participation in the programme, respondents' previous experiences in FGM practice, their willingness to subject their daughters to FGM, and reasons for behaviour modification or non-behaviour modification.

\subsection{Validity and Reliability of Instrument for Data Generation}

Experts in the Faculty of Arts, University of Nigeria assessed the relevance of the contents of the questionnaire to ensure its validity: objectivity and potency. Further, a test-retest method was carried out within an interval of two weeks in two towns outside Enugu State, namely: Ezzamgbo and Okpoto in Ebonyi State to test its reliability. The correlation analysis of responses from the two sets of tests showed a reliability of 0.80 .

\subsection{Method of Data Analysis:}

The data collected during the fieldwork was analyzed with the aid of one-sample t-test in the statistical package for social sciences (SPSS) version 20.0. However, the demographic data of the respondents and data generated from interviews were analyzed using frequency tables and percentages.

\section{Results and Discussion}

Table 1. Summary of demographic data collected from respondents

\begin{tabular}{|c|c|c|c|c|c|c|c|}
\hline \multirow[t]{2}{*}{ S/No. } & \multirow[t]{2}{*}{ Senatorial District } & \multicolumn{3}{|c|}{$\begin{array}{l}\text { Respondents' FGM } \\
\text { Personal Experience }\end{array}$} & \multicolumn{2}{|c|}{ Respondents' Family Experience } & \multirow[b]{2}{*}{ FGM:No } \\
\hline & & Total & Yes & No & No of Female kids & FGM: Yes & \\
\hline 1 & Enugu East & 51 & 49 & 2 & 117 & 117 & Nil \\
\hline 2 & Enugu West & 59 & 56 & 3 & 151 & 151 & Nil \\
\hline \multirow[t]{2}{*}{3} & Enugu North & 52 & 52 & Nil & 142 & 142 & Nil \\
\hline & Total & 163 & 158 & 5 & 410 & 410 & Nil \\
\hline
\end{tabular}

An analysis of Table 1 reveals that one hundred and fifty eight respondents representing 96.93\% experienced FGM, while only 5 respondents representing $3.07 \%$ were free from or did not experience FGM. The table further reveals that the respondents had a total number of 410 female children, excluding pregnancies. Out of this number, all of them, totalling $100 \%$ of the children were circumcised. Mothers who were circumcised gave up their own female children for circumcision. 


\subsection{Research Question 1}

There are negative experiences associated with FGM?

Table 2. One-sample t-test analysis of responses to research question one

\begin{tabular}{|c|c|c|c|c|c|c|c|}
\hline Question & $N$ & $S E$ Mean & $t$ & $d f$ & Significance & $\begin{array}{l}\text { Mean } \\
\text { Difference }\end{array}$ & $95 \% C I$ \\
\hline $\begin{array}{l}\text { There are negati } \\
\text { experiences } \\
\text { associated with } \\
\text { FGM. }\end{array}$ & 163 & .069 & 34.518 & 162 & .000 & 2.393 & $2.26-2.53$ \\
\hline
\end{tabular}

The result of the t-test analysis carried out on the data generated from the respondents concerning the existence of negative experiences associated with FGM in their communities is shown in Table 2. In Table 2, the t-test analysis of responses concerning the existence of negative experiences associated with FGM in the rural areas of Enugu State reveals a total mean of 2.39 and a standard deviation of .885. Further, the mean differences of the entire responses reveal a significant difference among respondents on the negative experiences associated with FGM, $t(162)=34.518, P=.000,95 \% \mathrm{CI}=2.26-2.53$.

\subsection{Research Question 2}

You participate in media programmes against FGM?

Table 3. One-sample t-test analysis of research question two

\begin{tabular}{llllllll}
\hline Question & $N$ & SE Mean & $\mathrm{t}$ & $d f$ & Significance & $\begin{array}{l}\text { Mean } \\
\text { Difference }\end{array}$ & 95\% CI \\
\hline $\begin{array}{l}\text { You participate in media programmes } \\
\text { against FGM }\end{array}$ & 163 & .067 & 28.682 & 162 & .000 & 1.926 & $1.79-2.06$ \\
\hline
\end{tabular}

The result of the t-test analysis carried out on the data generated from the respondents concerning the participation of rural women in media programmes against FGM is shown in Table 3. In Table 3, the t-test analysis of responses to issue concerning the participation of rural women in media programmes against FGM in Enugu State reveals a total mean of 1.93 and a standard deviation of .857. In addition, it reveals that the mean differences of the entire responses shows a significant difference in respondents' participation in media programmes against FGM, $t(162)=$ 28.682, $P=.000,95 \% \mathrm{CI}=1.79-2.06$

\subsection{Research Question 3}

You have accepted the message of the media campaign against FGM and modified your behaviour towards FGM?

Table 4. One-sample t-test analysis of research question three

\begin{tabular}{llllllll}
\hline Question & $N$ & $\begin{array}{l}S E \\
\text { Mean }\end{array}$ & $t$ & $d f$ & Significance & Mean Difference & $95 \%$ CI \\
\hline $\begin{array}{l}\text { You have accepted the message of the } \\
\text { media campaign against FGM and } \\
\text { modified your behaviour towards } \\
\text { FGM? }\end{array}$ & & & & & & & \\
\end{tabular}

The result of t-test analysis carried out on the responses of our respondents concerning their acceptance of the message for non-FGM as propagated by the media is shown in Table 4. In the Table 4, analysis of data reveals a total grand mean of 1.71 and a standard deviation of responses of .457. In addition, it reveals that the mean differences of the entire responses shows a significant difference in respondents' acceptance of the message of the media campaign against FGM and in modifying their behaviour towards FGM, $t(162)=47.625, P=.000,95 \% \mathrm{CI}$ 
$=1.63-1.78$.

Focus Group Discussion analysis reveals that majority of the respondents argue that FGM practice preserves their marriages because it controls or reduces women promiscuity, infidelity, and their associated divorce/marriage crises. When confronted with the issue of pains during childbirth, they argued that pain is synonymous with childbirth. Earlier findings made by scholars (e.g. Adeokun et al., 2006; Anuforo, Oyedele, \& Pacquino, 2004; Ehigiegba \& Selo-Ojeme, 1998) were that culture, tradition, sexual purity, future marriage stability, and aiding future childbirth, are the most common reasons for FGM practice. However, the findings manifest a consistent trend towards a shift from women's blind adherence to tradition and culture to their own conviction. This is important because practices based on individual conviction are easier to eradicate than those based on culture and tradition.

The grand mean response of 1.93, i.e. strongly disagree, reveals that majority of the rural women in Enugu state do not participate in the media campaign against FGM. This is because of people's perception of the programmes as anti-cultural (51\%), poor area network coverage (23\%), epileptic power supply (18\%), and lack of time to listen to, or watch the media programmes $(4 \%)$. Other factors like language and/or level of education, the timing of the media programmes, poverty and inability to purchase radio and/or television set have little or no impact at all. These findings explain why media sensitisation programme against FGM has failed to influenced or altered women's acceptance and practice of FGM in the rural areas of Enugu state. Without listening to the programme, how can they appreciate the message and adjust their behaviour pattern towards FGM? The implication of this finding for the campaign is that a more pro-active approach to media acculturation and media penetration is needed for the people to listen and accept the programmes.

Focus Group Discussion analysis reveals that $85 \%$ of the respondents see the contents of the media campaign as falsehood and propaganda. In addition, $100 \%$ of the respondents noted that the media campaign is a one-way communication flow that abhors interactions and feedback. This exacerbated the existing people's indifference to media programmes. This discourages the people from listening to or participating in the programme. The implication of this finding is that Nigeria media should imbibe the $21^{\text {st }}$ century media democratisation movement and implement the principles of press freedom. This will make the FGM campaign localised, indigenous, and people-oriented.

The findings reveal also that most of the elderly women interviewed were above 60 years and have neither suffered any disease/infection due to FGM nor heard about any of such experience within their locality. Equally, 92\% of our questionnaire respondents affirm the position of the elderly women, and in addition argued that no person or group has ever shown them films or evidences of people suffering or that are dead because of FGM practice. The reports of WHO (2008) and WHA (2008) indicate that FGM causes severe and irreversible physical and psychological harm on women girls and women throughout their lives. The implication of this for FGM behaviour change in the state is that the media campaign should integrate actual and visible documentaries of those that experienced these negative effects in the past irrespective of their locality. This will convince rural people to abandon the practice.

Further, the Focus Group Discussion analysis of responses to the human rights issues where $92 \%$ of the respondents holds that they are not being cheated by FGM practices. WHO (2008) and Insight (2010) observes that FGM violates women's right to health, security, and physical integrity; the right to be free from torture and cruel, inhuman or degrading treatment; and the right to life when the procedure results in death. This contradiction reveals why the human rights approach in the sensitization of people against FGM in the state is highly ineffective. This is because of their age-long belief and tradition that parents are responsible for their children's health, security, choice, and development till adulthood. They consider the human right argument as anti-cultural, neo-colonial and westernisation. UN (2009) observed that FGM is discriminatory in nature, and assigns girls and women an inferior position in the family and society. However, our results suggest that if women are side-lined in Enugu state, it is not because of FGM but tradition and culture. Further evidence shows that both sexes undergo the same circumcision in Enugu state. Therefore, there is no perception of cheating in FGM practice by females.

The respondents observe in their Focus Group Discussion responses also that the positive gains or advantages inherent in FGM override the presumed consequences among the rural people in Enugu State. These gains include sexual purity/future marriage stability $(48 \%)$, culture and tradition justification $(32 \%)$, and good health and safe delivery during pregnancy (14\%). Insight (2010) observed that reciprocal social expectations and beliefs system support the practice of FGM. The implication of this finding for the media campaign is that its programmes should be redesigned to focus on the modernisation of people's beliefs system in the state. The campaign need to prove the non-existence of certain consequence created by people's beliefs concerning none practice of FGM.

The study was hindered by the unwillingness of some pregnant women to respond to questions. It is necessary to 
carry out further and empirical research on the relationship between FGM and promiscuity and complications in women childbearing effort. If any form of direct relationship is established, further research is required on how to modernise the practice to avoid infections, diseases, and maternal death. Therefore, the paper recommends a re-packaging of the media campaign against FGM through the expansion of people's access to the media such as the introduction of phone-in programme from participant for purposes of asking questions, making comments, and feedbacks. The media should also embark on visual programmes to substantiate the claim that FGM practice leads to disease/infections and maternal death, and that non-practice of FGM does not have a direct relationship to promiscuity and marriage instability. Consequently, the government of Enugu State should create avenue for media debates and programmes on the pros and cons of FGM, particularly its antenatal and post-natal effects. In addition, network providers for the entire media industries operating in Enugu State should expand and modernise their infrastructures to ensure local reach and access. Finally, government should step up rural electrification projects and improve power supply in the rural areas to enable rural dwellers empower their electronic gadgets for news/information.

\section{Conclusions}

The practice of FGM is still prevalent in the rural areas of Enugu State in spite of media campaign against it. Media campaign against FGM in Enugu state is ineffective. Cultural values, poor network reception, epileptic power supply, inaccessible media, and the nature of the content of the campaign are responsible for the ineffectiveness. There is need to improve the media contents for campaign against FGM practice, and the development of pro-Igbo cultural programmes against FGM practice. Further empirical research on FGM-maternal health care in Enugu State is recommended.

\section{Competing Interests Statement}

The authors declare that there are no competing or potential conflicts of interest.

\section{References}

Abubakar, I., Iliyasu, Z., Kabir, M., Uzoho, C. C., \& Abdulkadir, M. B. (2004). Knowledge, attitude and practice of female genital cutting among antenatal patients in Aminu Kano Teaching Hospital, Kano. Nigerian Journal of Medicine, 13(3), 254-258.

Adeokun, D. L., Oduwole, M., Oronsaye, F., Gbogboade, A. O., Aliyu, N., \& Wumi, A. (2006). Trends in female circumcision between 1933 and 2003 in Osun and Ogun states, Nigeria (a cohort analysis). African Journal of Reproductive Health, 10(2), 48-56. https://doi.org/10.2307/30032458

Ahmadi, A. B. A. (Spring 2013). An Analytical Approach to Female Genital Mutilation in West Africa. International Journal of Women's Research, 3(1), 37-56.

Alo, O. A., \& Adetula, G. (2005). Myths and realities surrounding female genital mutilation (FGM) in Ekiti State of Nigeria. International Journal of Violence and Related Studies, 2(1), 315-321.

Anuforo, P. O., Oyedele, L., \& Pacquino, D. F. (2004). Comparative study of meanings, beliefs and practices of female circumcision among three Nigerian tribes in the United States and Nigeria. Journal of Transcultural Nursing, 15(2), 103-13. https://doi.org/10.1177/1043659603262486

Anyamene, A., Nwokolo, C., \& Anyachebelu, F. E. (2012). Strategies for Eradicating Female Genital Mutilation Practice: Implication for Counselling. International Review of Social Sciences and Humanities, 2(2), 62-67.

Apenda, A., \& Terna, A. (2009).Cultural dimension of female genital mutilation and its effect on the health of women in Africa. Benue Journal of Gender Studies, 1(1), 173-179.

Asemah, E. S. (2011). Mass media in the contemporary society. Jos: University press.

Babalola, S., Brastington, A., Agbasimato, A., Helland, A., Nwanguma, E., \& Onah, N. (2006). Impact of a communication programme on female genital cutting in Eastern Nigeria. Tropical Medicine \& International Health, 11(10), 1594-1603. https://doi.org/10.1111/j.1365-3156.2006.01701.x

BAOBAB for Women's Human Rights. (BAOBAB). (2002). Women's Access to Justice and Personal Security in Nigeria: A Synthesis Report. Lagos: BAOBAB for Women's Human Rights.

Barber, B. R. (1996). Jihad vs. McWorld: How globalism and tribalism are reshaping the world. USA: Ballantine

Barker, G., Ricardo, C., \& Nascimento, M. (2007). Engaging Men and Boys in Changing Gender-Based Inequity in Health: Evidence from Programme Interventions. World Health Organization, Geneva. Retrieved from http://www.who.int/gender/documents/Engaging_men 
Cassman, R. (2008). Fighting to Make the Cut: Female Genital Cutting Studied within the Context of cultural relativism. Northwestern Journal of international Human Rights, 6(1), 128-154.

Efua, D. (1994). Cutting the Rose, Female Genital Mutilation: The practice and its prevention. London: Minority Rights Group.

Ehigiegba, A. E., Selo-Ojeme, D. O., \& Omorogbe, F. I. (1998). Female circumcision and determinants in Southern Nigeria. East African Medical Journal, 75, 374-376.

Ibekwe, P. C., Onoh, R. C., Onyebuchi, R. C., Ezeonu, P. O., \& Ibekwe, R. O. (2012). Female Genital Mutilation in South-East Nigeria: A Survey on the Current Knowledge and Practice. Journal of Public Health and Epidemiology, 4(5), 117-122. https://doi.org/10.5897/JPHE11.194

Insight, I. (2010). The Dynamics of social change: Towards the Abandonment of Female Genital Mutilation/Cutting in Five African Countries. Florence, Italy: The UNICEF Innocenti Research Centre. Retrieved from www.unicef-irc.org/publications/

Kalu, L. E. (2010). The media and political communication in Nigeria. Journal of Media and Political Studies, 2(1), 1-12.

Kolawole, O. D., \& Anke, V. D. K. (2012). A Review of Determinant of Female Genital Mutilation in Nigeria. Journal of Medicine and Medical Sciences, 1(11), 23-34.

La-Barbera, C. M. (2009). Revisiting the Anti-female Genital Mutilation Discourse. Palermo: Diritto \& QuestioniPubbliche.

Mackie, G., \& LeJeune, J. (2009). Social dynamics of abandonment of harmful practices: a new look at the theory. InnocentiWorking Paper 2009-06, UNICEF Innocenti Research Centre, Florence, May.

Mandara, M. U. (2005). Female Genital Mutilation in Nigeria. International Journal of Gyneacology and Obstetrics, 9(3), 76-83.

McGuine, F. A. (2002). The Impact of Traditional Practice on Women in Africa. London: African Books limited

Mortensen, P. B., \& Serritzlew, S. (2004). Newspapers, agenda-setting, and local budgeting. Draft paper presented to The European Consortium for Political Research, Joint Sessions of Workshops - Uppsala 2004 Workshop number 15, p.17 Political Agenda-setting and the Media.

Nabudere, D. W. (2005). Human Rights and Cultural Diversity in Africa.Conference on the Fusion of Legal Systems and Concepts in Africa, Sept. 4th- 8th, at the Imperial Resort Beach Hotel, Entebbe.

Nwokolo, C.N. (2009). Psycho-social implications and counselling measures against female circumcision in Igbo land. Nigeria Journal of Teacher Education and Teaching, 7(8), 18-24.

Ofor, M. O., \& Ofole, N. M. (2015). Female Genital Mutilation: The Place of Culture and the Debilitating Effects on the Dignity of the Female Gender. European scientific Journal, 11(4), 112-121. https://doi.org/10.21275/v4i11.NOV151641

Ogbuoshi, L. I. (2011). Introduction to mass communication. Enugu: Newmoon Publishers.

Ogionwo, W. E. (2003). State and Dignity of Women in Traditional Religions. Calabar: Tonis Press.

Okeke, T. C., Anyaehie, U. S. B., \& Ezenyeaku, C. C. K. (Jan-Jun 2012). An Overview of Female Genital Mutilation in Nigeria. Annals of Medical and Health Science Research, 2(1), 70-73. https://doi.org/10.4103/2141-9248.96942

Okpanchi, E. (2005). Consequences of female genital mutilation on Nigeria women. In A. D. Menegbe (Ed.).The Humanities and Globalization: the African Perspective (pp. 54-63). Makurdi: Aboki Publisher.

Okpando, C. P. (2004). Africa Women: The Way Forward. Lagos: Akin Printing Press.

Pool, S. I. (1990). Technologies without Boundaries: On Telecommunication in a Global Age. Cambridge, MA: Harvard University Press. https://doi.org/10.4159/harvard.9780674422025

Protess, D., Cook, F., Doppelt, L., Ettema, J. S., Gordon, M. T., Leff, D. R., \& Miller, P. (1991). The journalism of outrage: investigative reporting and agenda building in America. New York: Guilford Press

Scott, R. (2005). Mass Media Research. California: Wadsworth Publishing Company.

Shah, G., Susan, L., \& Furcroy, J. (2009). Female circumcision: history, medical and psychological complications, and initiatives to eradicate this practice. Canadian Journal of Urology, 16(2), 4576-4579. 
Sharon, E. B. (2006). Community Education and Development. New York: Free press

Tufte, T., \& Mefalopulos, P. (2009). Participatory Communication: A Practical Guide. Working Paper, No. 170. The World Bank, Washington, DC. Retrieved from http://siteresources.worldbank.org/EXTDEVCOMMENG/Resources/Participatorycommu nication.pdf

U.S. Department of State. (2001). Nigeria: Report on Female Genital Mutilation (FGM) or Female Circumcision $(F C)$. Retrieved from http://www.state.gov/wi/r/s/rep/crfgm/10106pf.htm

United Nations. (2009). The Girl Child. Report of the Secretary-General, A/64/315, UN, New York, 21 August, para. 63.

UNICEF. (2005). Strategic Communication. Working Paper, United Nations Children's Fund Regional Office for South Asia. Retrieved from http://www.unicef.org/rosa/StrategicCommunication_forBehaviour andSocial_Change.pdf

Uturu, R. E. (2009). The impact of harmful traditional practices on educational development of the girl-child in Nigeria. Benue Journal of Gender studies, 1(1), 35-43.

WHA. (2008). Female Genital Mutilation. Resolution WHA61.16, agenda item 11.8, 24 May.

WHO. (2008). Eliminating female genital mutilation: an interagency statement-OHCHR, UNAIDS, UNDP, UNECA, UNESCO, UNFPA, UNHCR, UNICEF, UNIFEM, WHO. WHO, Geneva, March.

Women's Right Education Programme (WREP). (2006). Combating the Practice of Female Genital Mutilation in Three Local Government Areas of Benue State. Retrieved from http://www.wrepnig.org/reports/Document1.pdf?PHPSESSID=ab6dc078284b7cccf 0bb3f 47683ec8ef

\section{Copyrights}

Copyright for this article is retained by the author(s), with first publication rights granted to the journal.

This is an open-access article distributed under the terms and conditions of the Creative Commons Attribution license (http://creativecommons.org/licenses/by/4.0/). 